\section{External validation of EULAR/ACR classification criteria for idiopathic inflammatory myopathies}

We have read with great interest the article published by Jinnin et al, which was an external validation of sensitivity and specificity of the EULAR/ACR (European League Against Rheumatism / American College of Rheumatology) classification criteria for idiopathic inflammatory myopathies with a Japanese cohort. The title and article claim that this is the first external validation study. While this may be true for a Japanese cohort, our intention is to alert the readers to the earlier published validation studies that preceded this and help highlight the complete body of evidence that should be considered.

The idiopathic inflammatory myopathies (IIMs) are a group of uncommon disorders with a potential for significant mortality and morbidity. Progress in the understanding and management of these disorders has been hampered by the lack of validated criteria on which appropriate studies and clinical trials can be based. The classification criteria by the joint European League Against Rheumatism / American College of Rheumatology (EULAR/ACR) consortium ${ }^{1}$ were developed to address this problem. The criteria were developed from analysis of data collected over 10 years from 976 IIM and 624 non-IIM patients from multiple centres. An important acknowledged limitation was that the external validation did not include controls or comparators and was therefore able to consider sensitivity but not specificity. Further limitations were the low frequency of myositis-specific antibody (MSA) and MRI testing prompting the authors to call for further validation studies.

The report by Jinnin $e t a l^{2}$ is therefore a valuable contribution particularly as it addresses a specific population (Japanese), which was minimally represented in the original study.

The claim made in the title and body of the report that this is the first external validation study is however incorrect. There are other external validation studies ${ }^{3-7}$ that precede it and that were on public record prior to the final October 2019 revision date of the report.

Hočevar $e t a l^{3}$ and Zhang $e t a l^{6}$ had reported their findings in 2018 and May 2019, respectively, and we reported our validation study in Australian patients initially as a preliminary analysis to a domestic audience in May 2018. ${ }^{4}$ The final complete analysis was presented to an international audience at the October 2018 American College of Rheumatology Annual Scientific meeting ${ }^{5}$ and published in ACR Open Rheumatology online in August 2019.

We found that in our cohort the EULAR/ACR criteria had very high specificity but lower sensitivity, and lower optimal sensitivity and specificity cut points than that suggested in the EULAR/ACR report. We also explored the effect of MRI and an extended panel of myositis-associated antibodies and MSAs and showed in a logistic regression model that including them as covariates of the EULAR/ACR criteria improved the ability to discriminate between IIM and non-IIM patients.

The confidence with which clinicians may use newly developed classification criteria is determined in part by their validation in other populations and ideally drawing on patients from different geographic locations and ethnicity. Hence validation of the initial EULAR/ACR classification criteria for IIM in an Asian population ${ }^{2}$ is an important contribution. Our intention here is to alert the readers to the earlier published validation studies that preceded this and help highlight the complete body of evidence that should be considered.
Queenie Luu $\odot{ }^{1,2}$ Jessica Day, ${ }^{3,4}$ Alix Hall, ${ }^{5}$ Vidya Limaye, ${ }^{6}$ Gabor Major ${ }^{7,8}$ ${ }^{1}$ Department of Rheumatology, Canterbury Hospital, Campsie, New South Wales, Australia

${ }^{2}$ South Western Sydney Clinical School, University of New South Wales, Liverpool, New South Wales, Australia

${ }^{3}$ Department of Rheumatology, Royal Adelaide Hospital, Adelaide, South Australia, Australia

${ }^{4}$ School of Pharmacy \& Medical Sciences, University of South Australia, Adelaide, South Australia, Australia

${ }^{5}$ Hunter Medical Research Institute, The University of Newcastle, New Lambton, New South Wales, Australia

${ }^{6}$ Discipline of Medicine, The University of Adelaide, Adelaide, South Australia, Australia ${ }^{7}$ Department of Rheumatology, John Hunter Hospital, New Lambton Heights, New South Wales, Australia

${ }^{8}$ Faculty of Medicine, The University of Newcastle, Callaghan, New South Wales, Australia

Correspondence to Dr Queenie Luu, Rheumatology, Canterbury Hospital, Campsie, NSW 2194, Australia; queenie.luu@gmail.com

Contributors QL and GM drafted this correspondence. JD, AH and VL were involved in revising and editing the correspondence.

Funding The authors have not declared a specific grant for this research from any funding agency in the public, commercial or not-for-profit sectors.

Competing interests None declared.

Patient and public involvement Patients and/or the public were not involved in the design, or conduct, or reporting, or dissemination plans of this research.

Patient consent for publication Not required.

Provenance and peer review Not commissioned; internally peer reviewed.

(c) Author(s) (or their employer(s)) 2020. No commercial re-use. See rights and permissions. Published by BMJ.

\section{Check for updates}

To cite Luu Q, Day J, Hall A, et al. Ann Rheum Dis Epub ahead of print: [please include Day Month Year]. doi:10.1136/annrheumdis-2020-217568

Received 10 April 2020

Accepted 15 April 2020

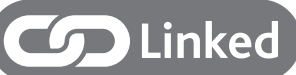

- http://dx.doi.org/10.1136/annrheumdis-2020-217635

Ann Rheum Dis 2020;0:1. doi:10.1136/annrheumdis-2020-217568

ORCID iD

Queenie Luu http://orcid.org/0000-0002-4723-7545

\section{REFERENCES}

1 Lundberg IE, Tjärnlund A, Bottai M, et al. 2017 European League against Rheumatism/ American College of rheumatology classification criteria for adult and juvenile idiopathic inflammatory myopathies and their major subgroups. Ann Rheum Dis 2017;76:1955-64.

2 Jinnin M, Ohta A, Ishihara S, et al. First external validation of sensitivity and specificity of the European League Against Rheumatism (EULAR)/American College of Rheumatology (ACR) classification criteria for idiopathic inflammatory myopathies with a Japanese cohort. Ann Rheum Dis 2020;79:387-92.

3 Hočevar A, Rotar Z, Krosel M, et al. Performance of the 2017 European League against Rheumatism/American College of rheumatology classification criteria for adult and juvenile idiopathic inflammatory myopathies in clinical practice. Ann Rheum Dis 2018;77:e90-e.

4 Luu Q, Major G. Performance of the 2017 European League against rheumatism / American College of rheumatology (EULAR/ACR) classification criteria for adult idiopathic inflammatory myopathies (IIM) in clinical practice in an Australian cohort. Internal Medicine Journal 2018;48:7.

5 Luu Q, Day JH A, Limaye V, et al. Performance of the 2017 European League against rheumatism / American College of rheumatology (EULAR/ACR) classification criteria for adult idiopathic inflammatory myopathies (IIM) in an Australian cohort. Arthritis Rheumatol 2018;70.

6 Zhang X, Yang X, Ji L, et al. Validation of 2017 classification criteria for adult and juvenile idiopathic inflammatory myopathies proposed by EULAR/ACR in Chinese patients. Int J Rheum Dis 2019:22:1278-82.

7 Luu Q, Day J, Hall A, et al. External validation and evaluation of adding MRI or extended myositis antibody panel to the 2017 EULAR/ACR myositis classification criteria. ACR Open Rheumatol 2019;1:462-8. 